\title{
Some Aspects of Structural Modeling of Damage Accumulation and Fracture Processes in Metal Structures at Low Temperature
}

\author{
Valeriy Lepov, Albert Grigoriev, Valentina Achikasova, and Kyunna Lepova \\ V. P. Larionov's Institute of Physical-Technical Problems of the North, SB RAS, Yakutsk677980, Russia \\ Correspondence should be addressed to Valeriy Lepov; lepov@iptpn.ysn.ru
}

Received 4 December 2015; Accepted 1 June 2016

Academic Editor: Theodoros C. Rousakis

Copyright (C) 2016 Valeriy Lepov et al. This is an open access article distributed under the Creative Commons Attribution License, which permits unrestricted use, distribution, and reproduction in any medium, provided the original work is properly cited.

\begin{abstract}
The problem of brittle fracture of structures at low temperature conditions connected to damage accumulation and ductile-brittle transition in metals. The data for locomotive tire contact impact fatigue and spalling are presented. The results of experimental testing showed the impact toughness drop at low temperature. The internal friction method was applied to revealing of the mechanism of dislocation microstructure changes during the low temperature ductile-brittle transition. It has been shown for the first time that the transition is not connected to interatomic interactions but stipulated by thermofluctuation on nucleus such as microcracks and by their further growth and coalescence. From now on, the proposed mechanism would be used for theoretical and numerical modeling of damage accumulation and fracture in materials.
\end{abstract}

\section{Introduction}

It is well known that during the low temperature climate operation the catastrophic breakdown of structure and machine elements often occurred. In that case the plasticity properties fall and the character of fracture changes from ductile to brittle $[1,2]$. The significant loss of safety and economic efficiency occurred in the operation of railway equipment in extremely low climatic temperatures conditions [3, 4]. This leads to growth of energy and resource intensity of transportation. Special actuality of this problem is considering the construction of new rail lines and increase of cargo turnover. The most important units of railway equipment are tire and rail. Their durability and reliability significantly affect operating costs, and destruction is unacceptable because they pose a clear threat to traffic safety. The railroad located on territory of the Republic of Sakha (Yakutia) in Siberia (Russia) is distinguished by low climatic temperatures and acutely continental climate [5]. The period of subzero extends about 210 days and the minimum of temperature reaches $60^{\circ} \mathrm{C}$ below zero. The difference of the average temperature achieves $70^{\circ} \mathrm{C}$ and more per season.

The diversity of the phenomenon of ductile-brittle transition is reflected by the factors affecting the type of fracture: both internal and external. Thus the chemical composition and the structure of the material reflect the physical nature of the phenomenon, and the loading rate, temperature, type of stress-strain state, and the size of the structure define the mechanical nature, respectively. It should be noted that the structural mechanism of the process occurring in the range of ductile-brittle transition therefore still remains undetermined. Nevertheless the existence of the phenomenon is well studied by optical and electronic metallography. Image in Figure 1 demonstrated the boundary of ductile (on upperright part) and brittle (on bottom-left part) mechanism of fracture.

The next step will be the multiscale modeling of damage accumulation and fracture. It should include the growth and coalescence mechanism of ductile pores and brittle small cracks and use the data of microstructure evolution on nano- and microscales also [6]. The stress and strain distribution partially accords with the thermodynamically consistent theory of elastoplasticity coupled with nonlocal damage in the strain space which was used $[7,8]$. The coupling of critical level of damage and strain invariants ratio [9] defines the crack opening conditions and coalescence with the main crack [10]. 


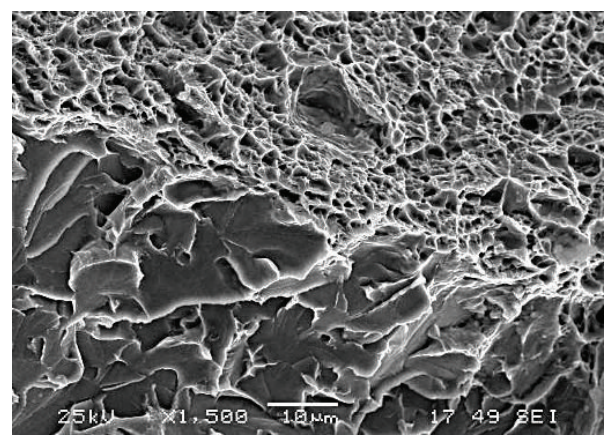

FIGURE 1: Microstructural image demonstrated the low temperature ductile-brittle transition in structural steel 09G2.

TABLE 1: Chemical composition of steel, mass $\%$.

\begin{tabular}{cccccc}
\hline Element & $\mathrm{C}$ & $\mathrm{Si}$ & $\mathrm{Mn}$ & $\mathrm{P}$ & $\mathrm{S}$ \\
\hline Content & 0,6 & 0,33 & 0,83 & 0,02 & 0,02 \\
\hline
\end{tabular}

\section{Materials and Methods}

The locomotive tires are exposed to influence of various loadings during operation. Material of the wheel of this locomotive element is merged in the complex stress state. So the internal and superficial defects are developed and damage plastic deformation and difficult tension take place.

2.1. Materials. The chemical composition of the locomotive tear bandage steel is shown in Table 1 and meets the requirements of the standard for such material [3].

The results of standard tension test for this steel do not have a great gulf fixed for mechanical properties (as yielding, breaking point, and tensile strain) at room and low temperature (see Table 2). The deformation curves are shown in Figure 2; and numbers 1-4 indicate samples.

But because the bandage of locomotive tire is operated not only in a wide range of working temperatures, in static and dynamic loading too the principle is to study the impact toughness of the material of the band, as positive $\left(20^{\circ} \mathrm{C}\right)$ and below freezing $\left(-20,-40\right.$, and $\left.-60^{\circ} \mathrm{C}\right)$ also. Table 3 shows the results of impact test of bandage steel and average values for three or five samples.

These values have been approximated by splines for further application (see Figure 3) [4].

2.2. Experimental Methods. The method of internal friction is one of the most sensitive methods in the study of the fine structure of metals and alloys. Measurement of internal friction runs in a wide range of frequencies. Measurement in the ductile-brittle transition of materials with BCC lattice is conveniently carried out at low frequencies (of the order of a few hertz), because the internal friction is sensitive to various disturbances and alterations of the structure at the level of crystal lattice and therefore is often used by researchers to examine the actual defect structure of crystals. In the present work, measurements of internal friction held by the method of free torsional vibrations widely used for dynamic mechanical analysis of metallic materials $[11,12]$.

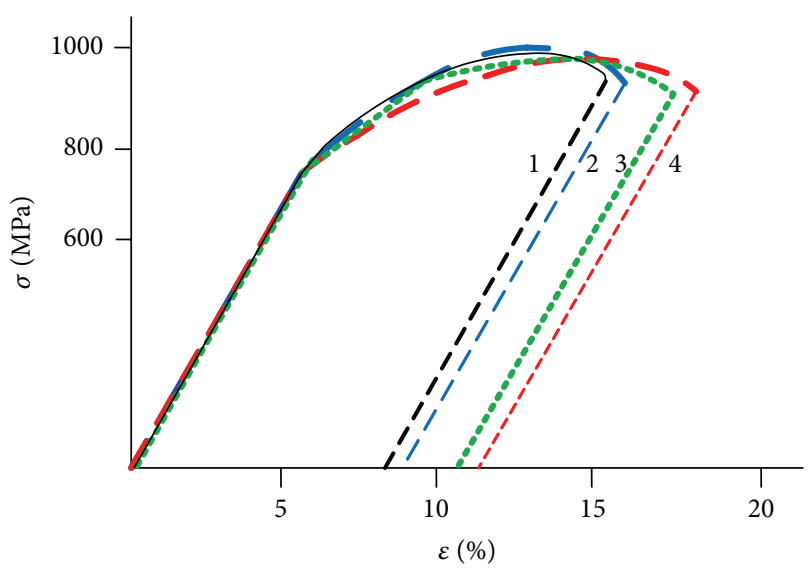

FIgURE 2: The deformation curves for tensile test.

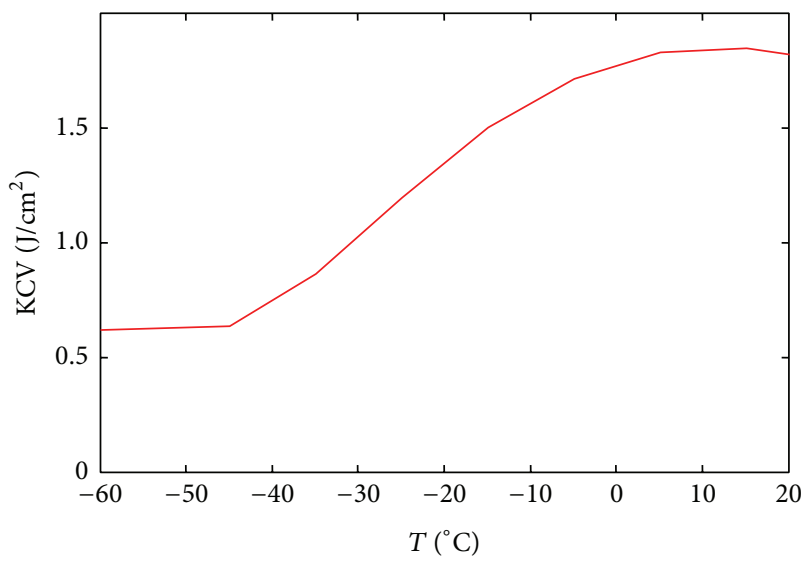

FIGURE 3: Approximation curve for impact toughness.

TABLE 2: Results of standard tensile test.

\begin{tabular}{lccc}
\hline$T,{ }^{\circ} \mathrm{C}$ & $\sigma_{T}$ & $\sigma_{B}$ & $\delta$ \\
\hline \multirow{3}{*}{ Room } & 708,97 & 1067,77 & 10,61 \\
& 686,12 & 1012,94 & 10,14 \\
& 705,40 & 1030,90 & 10,09 \\
\hline \multirow{3}{*}{-50} & $\mathbf{6 9 0 , 1 6}$ & $\mathbf{1 0 3 7 , 2}$ & $\mathbf{1 0 , 2 8}$ \\
\hline & 747,61 & 1035,3 & 8,64 \\
& 769,85 & 1135,21 & 8,93 \\
& 749,77 & 1029,49 & 8,33 \\
\hline
\end{tabular}

The reverse torsion pendulum has been used as the implementation of internal friction method. The lower end of test sample in the experiment has the form of a wire and was fixed stationary one. The upper end was rigidly connected to the inertial detail, suspended on torsion bars. The system was excited by torsional vibration. After removal of the driving force, the pendulum did damped oscillations. Main parameters of oscillations were measured (only the change of vibration amplitude, i.e., the number of oscillations here) to allow the calculation of the viscoelastic characteristics of the material sample [13]. 
TABLE 3: Results of test for impact toughness KCV.

\begin{tabular}{lcccc}
\hline$T,{ }^{\circ} \mathrm{C}$ & 20 & -20 & -40 & -60 \\
\hline & 2,29 & & & 0,70 \\
& 1,75 & 1,33 & 0,71 & 0,58 \\
$\mathrm{KCV}, \mathrm{J} / \mathrm{cm}^{2}$ & 1,69 & 1,37 & 0,54 & 0,74 \\
& 1,72 & 1,38 & 0,96 & 0,51 \\
& 1,64 & & & 0,67 \\
\hline Average & $\mathbf{1 , 8 2}$ & $\mathbf{1 , 3 6}$ & $\mathbf{0 , 7 3}$ & $\mathbf{0 , 6 2}$ \\
\hline
\end{tabular}

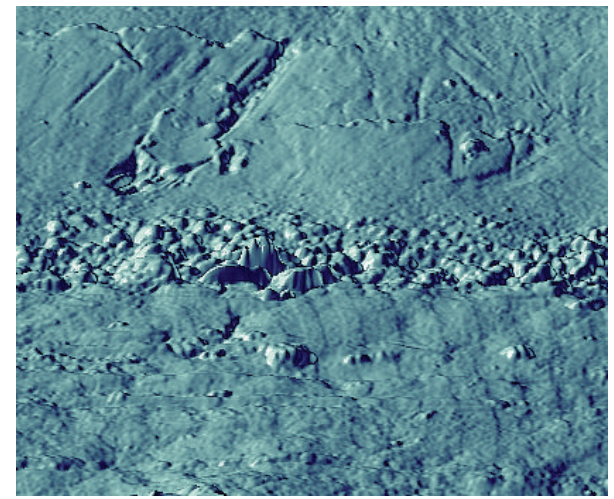

FIGURE 4: STM-image of the steel probe deformation surface with grain boundary.

As the test material, in this case structural steel 09G2 was selected. The test material has BCC lattice, which is characterized by low temperature ductile-brittle transition. Investigated wire samples have a diameter of $1 \mathrm{~mm}$ and working length $10 \mathrm{~cm}$. The relative deformation of the order of 10-5 has been defined at the frequency of oscillation of pendulum about $1 \mathrm{~Hz}$.

The important advantage of combined structural models should be mentioned also. It is the ability to find a way of experimental data obtained for one of the kinds of loading and behavior of the material, to the other, and combine experimental data related to various kinds of stress state and external influence.

The source data for the models are the sizes and quantitative characteristics of the distribution of defects at different structural levels obtained on the basis of scanning probe and optical microscopy and fractography, characterized by the fractal dimension, and it changes in the damage accumulation process.

Structural level in this case means the area of the extent to which the prevailing is certain defect structures (e.g., vacancy, dislocation, dislocation cluster, crack, micropore, strip shift, and nonmetallic inclusion). Structural levels sometimes could match the scale. Figure 4 presents the deformation surface image of low-alloyed steel plane probe near the rupture [14]. The image was obtained by STM and has $5 \times 5 \mu \mathrm{m}$ size. Just through the middle of the image a grain boundary passes with some structural defects around (small cracks, slip bends, and twins).

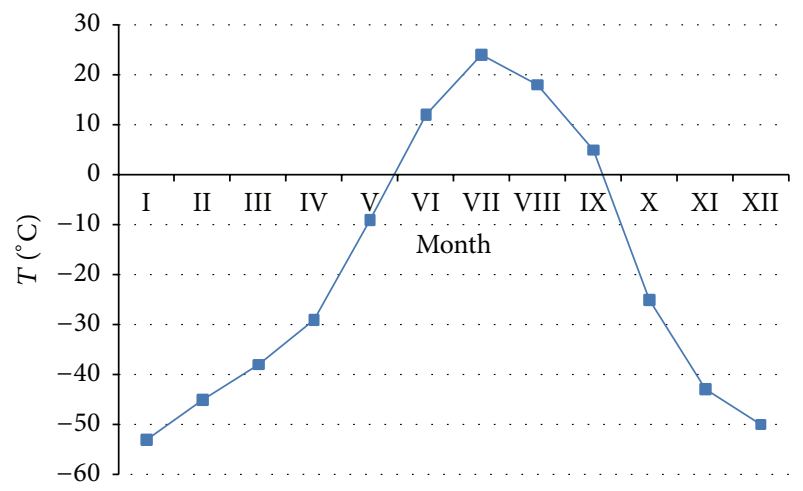

FIGURE 5: Minimal average month temperatures per five years in Tommot city.

\section{Results and Discussion}

The modeling of damage accumulation processes should consider the complex effects of high-cycle fatigue and lowcycle impact loading. The impact toughness as shown in Table 3 greatly depends on the test temperature. So the overall damage $\Psi$ could differentiate for high-cycle fatigue damage $\Psi_{F}$ and low-cycle impact damage $\Psi_{L}[9]$ :

$$
\Psi=\Psi_{F}+\Psi_{L}=\frac{1}{N} \sum_{i=1}^{N} \Psi_{F i}+\frac{1}{K} \sum_{k=1}^{K} \Psi_{L k}
$$

where $\Psi_{F i}$ is damage during fatigue $i$-cycle, $\Psi_{L k}$ is damage during impact $k$-cycle, $N, K$ are appropriate cycles value. For operation at low temperatures the fatigue damage of tire has reduced but the impact damage significantly grown.

In Figure 5 the time-average temperature on railroad track section near Tommot city has been shown. The appropriate toughness KCV could be found according to curve in Figure 3. The damage has been calculated taking into account the associated flow rule and $J$-integral dependence as [4]

$$
\Psi_{L}=\sum_{j=1}^{K}\left[\left(1-\frac{\mathrm{KCV}_{j}}{\mathrm{KCV}_{0}}\right)^{m}\right],
$$

where $\mathrm{KCV}_{0}, \mathrm{KCV}_{j}$ are impact toughness at room temperature and in $j$-damage condition accordingly and $m \sim$ $0,25, \ldots, 0,3$ is depending of material and stress state factor. The derivation of this empirical formula is based on connection between the stress intensity factor and $J$-integral, on the one hand, and proportion between values of stress intensity factor and impact toughness KCV, established experimentally for the high-strength steels, on the other hand $[15,16]$.

The mechanism of dislocation movement on microscale could be established by an internal friction measurement. Also the internal friction is one of the main methods for determination of energy dissipation localization in low temperature ductile-brittle transition [12]. The experiment by pendular oscillator for wire samples of structured lowalloyed steel 09G2 (content is about 0,1\% carbon and 2\% manganese) was carried out. The measurements of temperature dependence for internal friction of both tempered and 


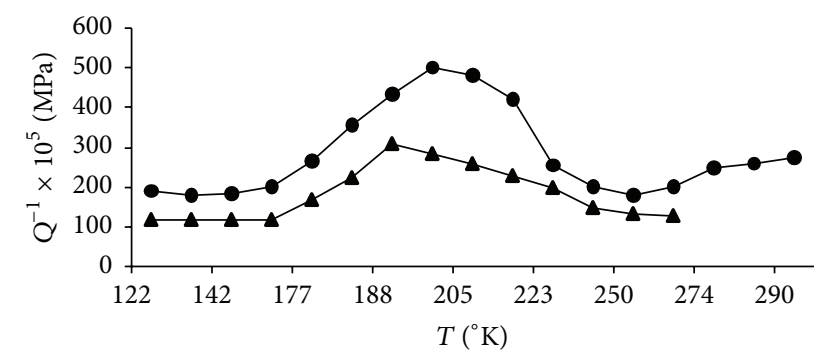

FIGURE 6: Temperature curve of internal friction of the testing steel.

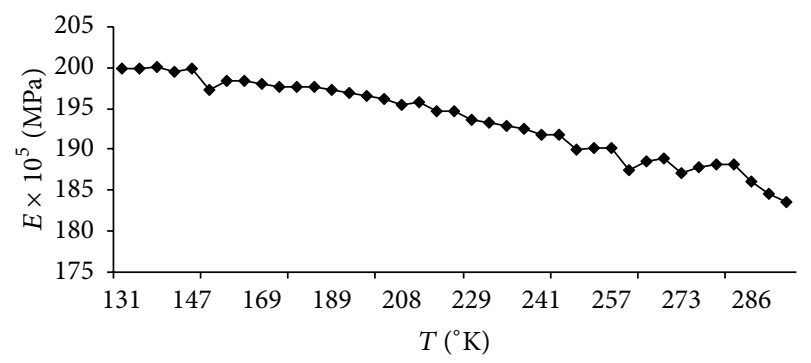

FIGURE 7: Temperature dependence of Young's modulus for testing steel.

annealed samples of the test material in the temperature range $100-300 \mathrm{~K}$ have been used. Concerning the interpretation of internal friction data the magnitude was determined by the next equation [11]:

$$
Q^{-1}=\frac{\ln K}{\pi} \frac{1}{n},
$$

where $Q^{-1}$ is the inverse mechanical quality factor, $n$ is the number of oscillations within the reduction of the amplitudes of the oscillations, and $K$ is a number indicating how many times the initial amplitude decreases for $n$ oscillations.

On the temperature curve of internal friction of the investigated steel is observed a maximum in the range of 160 $240 \mathrm{~K}$ (see Figure 6). Maximum of the curve for the tempered sample is higher than that of the annealed sample. The maximum of activation energy is calculated at the frequency shift and achieved a value of $0,2 \mathrm{eV}$. The interval of existence of this maximum steel 09G2 coincides with the interval of existence of ductile-brittle transition under impact toughness test.

During the experiment a temperature dependence of Young's modulus by resonance method has been investigated. The natural frequencies of a sample of steel 09G2 has been also determinate. The temperature dependence of the modulus of elasticity represents a monotonously increasing with decreasing temperature, a linear relationship in the range of ductile-brittle transition (see Figure 7).

Analytical possibilities of the method of internal friction allow obtaining the necessary information to study the early stages of damage in the area of ductile-brittle transition. The local changes in the submicroscopic structure of material occur in conditions of microstrains. Methods of mechanical spectroscopy allow evaluating the stages of development of the degradation processes and accumulation of the damage of deformed low-carbon steels [4]. There are a number of dislocation mechanisms responsible for low temperature inelastic scattering energy in various metals and alloys with BCC lattice. It can be thermal or geometric kinks in the motion of dislocations, interaction of dislocations with point defects, and the change in the density of mobile dislocations [11-13].

Stochastic model of crack growth and fracture in multiphase heterogeneous material is based on the mechanism triggered by stresses opening small cracks or pores on particles or ruptures of material [7-10, 14, 15].

Further viscoplastic growth and mutual coalescence of defects provide the crack propagation. Figure 8 showed the Web-oriented visualization examples of crack growth on microdefects. Algorithm has been realized by modern version of Java script language $[16,17]$. Modification of the model can be connected with application to a wide range of phenomena, for example, the accumulation of damage in porous media, materials with multiple phase transitions, including evaporation, melting, and freezing, and the secondorder phase transition [18-21].

\section{Summary}

The new criterion and approach of damage estimation for locomotive tire in extreme uncertainty conditions are offered. It is revealed that the lifetime of tire is significantly sensitive to impact strength at low temperature during operation.

Monotonic temperature dependence of Young's modulus in the range of ductile-brittle transition leads to confirming hypothesis about the dislocation and phonon mechanism of the phenomenon. Selection of the structural level occurs according to the classical Hamilton principle of stationary action or least action. In this case the rupture of atomic bonds occurs on athermal thermofluctuation mechanism in the inelastic scattering of phonons and under the action of tensile stresses, which can be appropriately modeled numerically. It should be noted that the revealing mechanism of internal friction of nano- and microcrystalline steels and alloys makes possible the building of theoretical and numerical models of the damage accumulation and fracture of the materials with a variable temperature-dependent structure.

So the new visualization possibilities of programming of damage accumulation and fracture processes presented in this paper too. The possibility of crack growth under the lowcycling and dynamic load and in cases of complex loading is examined.

\section{Conclusions}

This paper aims at experimental verification aspects of multiscale structural Web-oriented modeling of damage accumulation and fracture of heterogeneous materials. In very cold climate conditions the low temperature ductile-brittle transition in BCC-steel and alloys has a great significance. In such a practical problem like the strength of locomotive tire, for example, it is important to take into account the distribution of minimal temperature per calendar year and experimental dependence of impact toughness to reveal the 


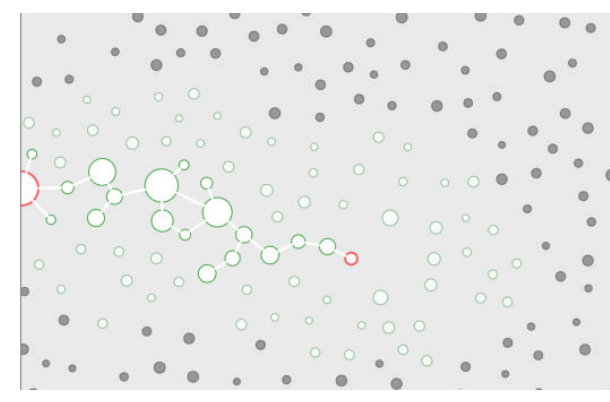

(a)

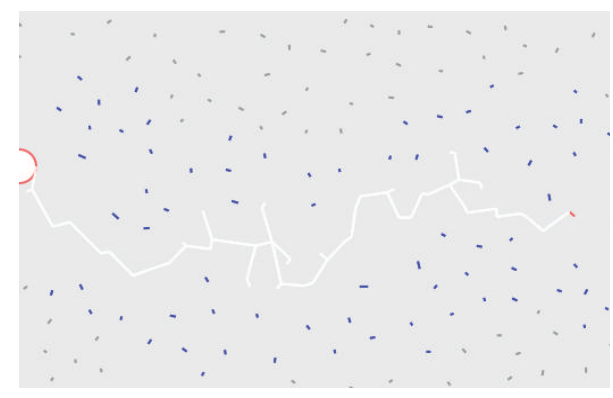

(b)

FIGURE 8: Java script visualization examples of crack growth on (a) micropores and (b) small cracks.

ductile-brittle transition range. The dislocation mechanism of such transition was showed by the amount of dissipation energy during the internal friction test. Then for modeling of the damage accumulation process and pores growth and crack brunching it is necessary to bring the nonlocal viscoelastic approach the thermodynamically consistent theory of elastoplasticity. For the Web-oriented visualization rendition the plane and stochastic approximation of crack distribution in multiscale structure has been used. The next step should be the connection between the modeling of material and prediction of real structure lifetime. Besides the transport this approach is highly desired in potentially dangerous industrial objects such as electricity and thermal power plants.

\section{Competing Interests}

The authors declare that they have no competing interests.

\section{Acknowledgments}

This research has been partially supported by Russian Foundation for Basic Research (Project 15-41-05010) and Federal Agency of Scientific Organization of Ministry of Science and Education of Russian Federation.

\section{References}

[1] A. Y. Krasovskii, "Ductile-to-brittle transition temperature as a measure of the crack resistance of steels," Strength of Materials, vol. 17, no. 10, pp. 1439-1446, 1985.

[2] V. I. Trefilov, Ed., Strain Hardening and Fracture of Polycrystalline Metal, Naukova dumka, Kiev, Ukraine, 1989 (Russian).

[3] A. V. Grigoriev and V. V. Lepov, "The mechanism of damage accumulation and fracture of railroad wheel material in condition of the North," Vestnik Severo-Vostochnogo Federal'nogo Universiteta, vol. 9, no. 1, pp. 79-85, 2012.

[4] A. V. Grigoriev and V. V. Lepov, "Assessment of the service life of rail equipment operating in extreme conditions of the North," Zavodskaja Laboratoria. Diagnostika Materialv, vol. 81, no. 12, pp. 42-48, 2015 (Russian).

[5] M. Weller, "Characterization of high purity bcc metals by mechanical spectroscopy," Le Journal de Physique IV, vol. 5, pp. C7-199-C7-204, 1995.
[6] V. Lepov, A. Ivanova, V. Achikasova, and K. Lepova, "Modeling of the damage accumulation and fracture: structural-statistical aspects," Key Engineering Materials, vol. 345-346, pp. 809-812, 2007.

[7] F. Marotti De Sciarra, "Hardening plasticity with nonlocal strain damage," International Journal of Plasticity, vol. 34, pp. 114-138, 2012.

[8] F. M. Marotti de Sciarra, "A nonlocal model with strain-based damage," International Journal of Solids and Structures, vol. 46, no. 22-23, pp. 4107-4122, 2009.

[9] V. Lyakhovsky, Y. Hamiel, and Y. Ben-Zion, "A non-local viscoelastic damage model and dynamic fracturing," Journal of the Mechanics and Physics of Solids, vol. 59, no. 9, pp. 1752-1776, 2011.

[10] V. Lepov and A. Loginov, "Non-Markovian evolution approach to structural modeling of material fracture," World Journal of Engineering, vol. 9, no. 3, pp. 207-212, 2012.

[11] Y. Kogo, Y. Iijima, N. Igata, and K. Ota, "Internal friction of carbon-carbon composites at elevated temperatures," Journal of Alloys and Compounds, vol. 355, no. 1-2, pp. 148-153, 2003.

[12] V. Lepov, V. Achikasova, A. Ivanova, and K. Lepova, "Lowtemperature ductile-brittle transition in metals: the micromechanics and modeling," in Proceedings of the 23rd Annual International Conference on Composites or Nano Engineering, Chengdu, China, 2015.

[13] M. S. Blunter and Y. V. Piguzov, Eds., The Method of Internal Friction in Physical Metallurgy Studies, Metallurgija, Moscow, Russia, 1991 (Russian).

[14] V. V. Lepov, A. M. Ivanov, B. A. Loginov et al., "The mechanism of nanostructured steel fracture at low temperatures," Nanotechnologies in Russia, vol. 3, no. 11-12, pp. 734-742, 2008.

[15] S. A. Golovin and S. A. Pushkar, Microplasticity and Fatigue of the Metals, Metallurgija, Moscow, Russia, 1980 (Russian).

[16] K. B. Broberg, "Computer demonstration of crack growth," International Journal of Fracture, vol. 42, no. 3, pp. 277-285, 1990.

[17] E. A. Arkhangel'skaya, V. V. Lepov, and V. P. Larionov, "The role of defects in the development of delayed fracture of a damaged medium under the effect of hydrogen," Materialovedenie, vol. 8, pp. 7-10, 2003.

[18] C. A. Reddy, "Strengthening mechanisms and fracture behavior of $7072 \mathrm{Al} / \mathrm{Al}_{2} \mathrm{O}_{3}$ metal matrix composites," International Journal of Engineering Science and Technology, vol. 3, no. 7, pp. 609060100, 2011.

[19] S. Nasrazadani and A. Raman, "The application of infrared spectroscopy to the study of rust systems-II. Study of cation 
deficiency in magnetite $\left(\mathrm{Fe}_{3} \mathrm{O}_{4}\right)$ produced during its transformation to maghemite $\left(\gamma-\mathrm{Fe}_{2} \mathrm{O}_{3}\right)$ and hematite $\left(\alpha-\mathrm{Fe}_{2} \mathrm{O}_{3}\right)$," Corrosion Science, vol. 34, no. 8, pp. 1355-1365, 1993.

[20] D. M. Levin, A. N. Chukanov, and A. A. Yakovenko, "The application of mechanical spectroscopy to the study of substructural degradation and the initial stages of fracture of steels," Izvestija of Tula's State Univerity, Natural Sciences, vol. 18, pp. 1625-1626, 2013.

[21] N. Shahidzadeh-Bonn, P. Vié, X. Chateau, J.-N. Roux, and D. Bonn, "Delayed fracture in porous media," Physical Review Letters, vol. 95, no. 17, Article ID 175501, 4 pages, 2005. 


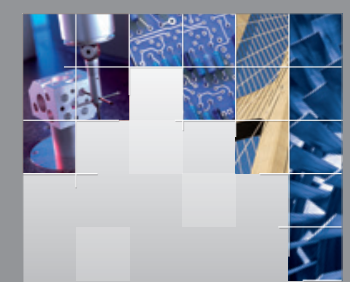

\section{Enfincering}
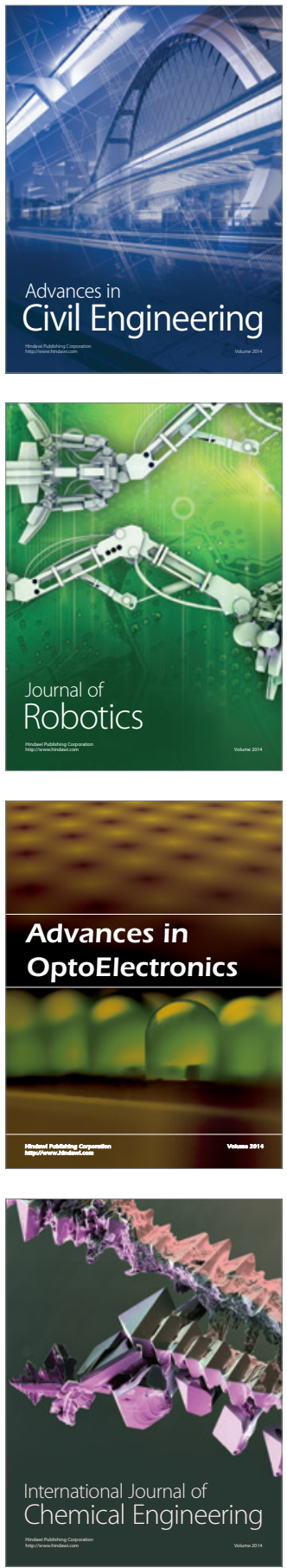

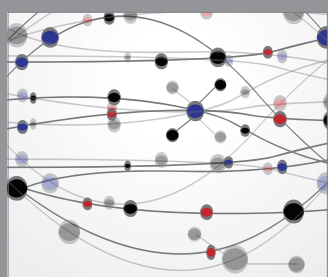

The Scientific World Journal

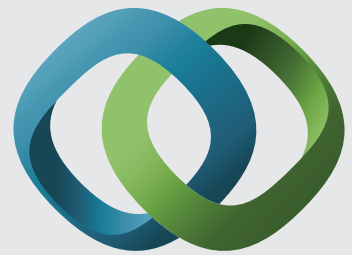

\section{Hindawi}

Submit your manuscripts at

http://www.hindawi.com
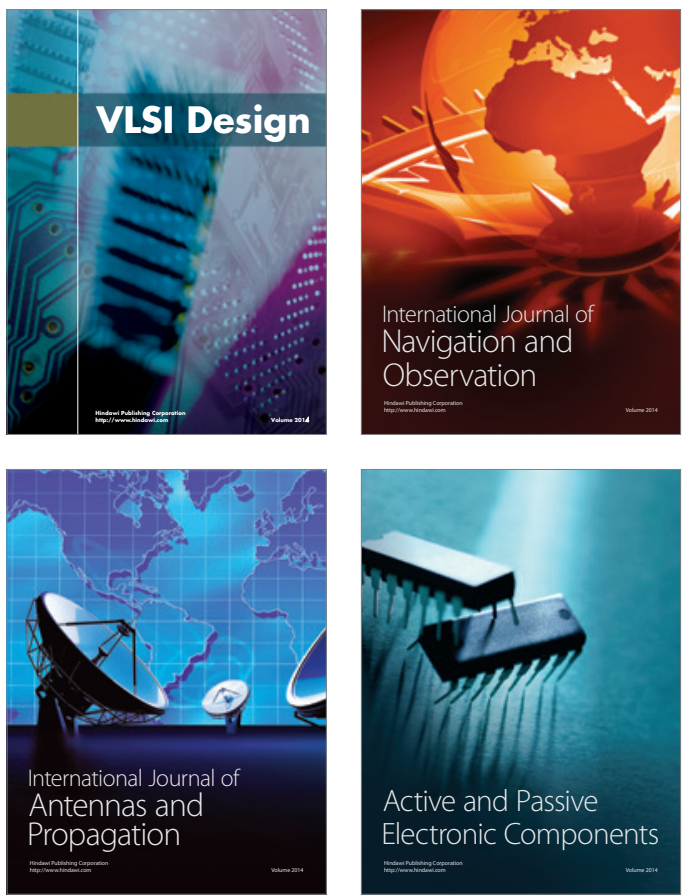
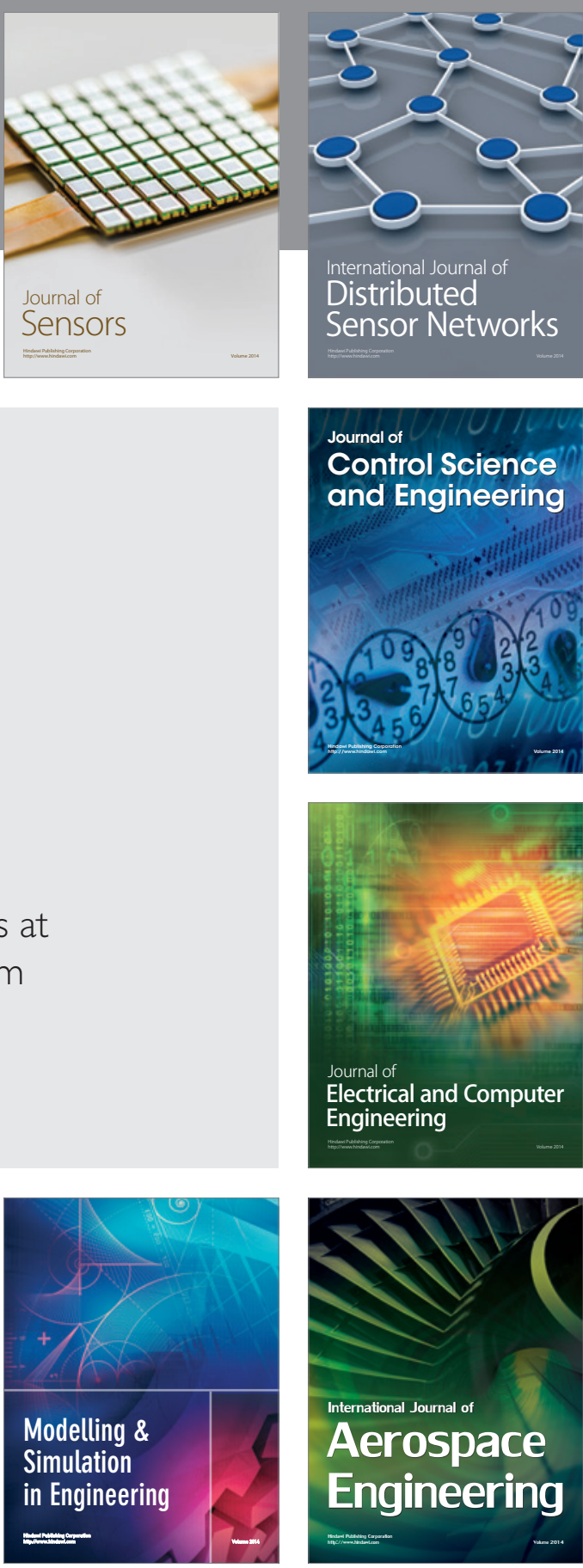

International Journal of

Distributed

Sensor Networks

Journal of

Control Science

and Engineering
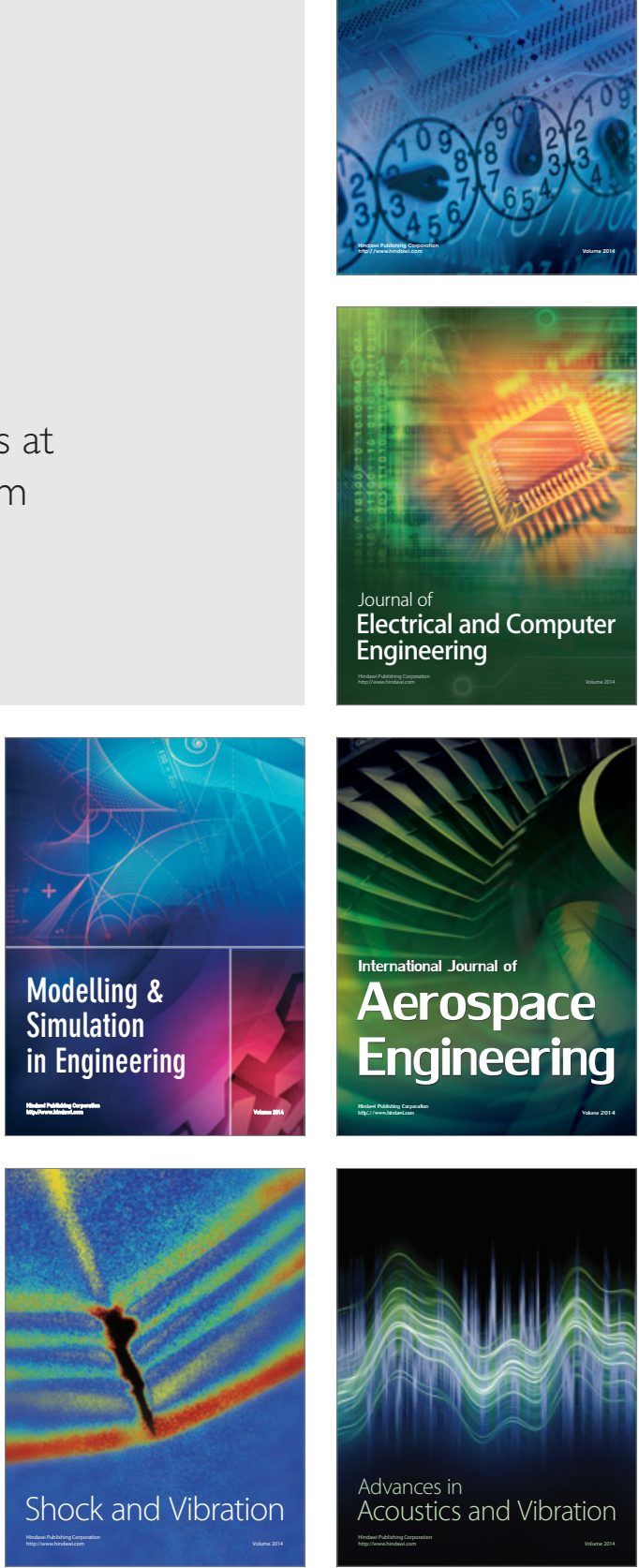